\title{
Error Analysis of English Sentence Structure in Students' Written Paragraphs
}

\author{
Dike Sundari \\ Institut Agama Islam Negeri (IAIN) Curup \\ dikesundari97@gmail.com \\ Jumatul Hidayah \\ Institut Agama Islam Negeri (IAIN) Curup \\ hidayah_jumatul@yahoo.com \\ Sarwo Edy \\ Institut Agama Islam Negeri (IAIN) Curup \\ edywong59@yahoo.com
}

Farida Esmianti

Poltekkes Kemenkes Bengkulu

faridaesmianti15@gmail.com

\begin{abstract}
This research aimed to find out the types of sentence structure errors in English paragraphs written by tertiary English students and the factors causing the errors. This research employed an explanatory mixed-method design. Fourth-semester students from the English department of IAIN Curup were engaged as the subjects of this research. Positivism-governed document analyses and constructivism-based interviews were conducted to solicit the data as desired. The quantitative findings garnered from document analyses endorsing a ready-to-use construct proposed by Dulay, Burt, and Krashen (1982), revealed that there were four types of sentence structure errors students made, namely omission, addition, misformation, and misordering. Those types of errors were exhibited in a proximate
\end{abstract}

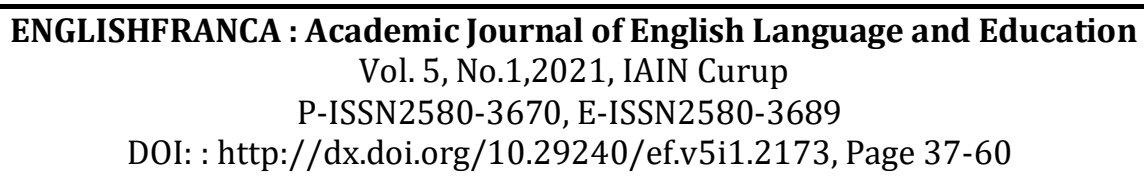


composition which meant that the students had compatible difficulties in terms of the four types of errors. As uncovered from students' writing works, the four types of errors were found in the domains of words, phrases, and clauses. Subsequently, the qualitative findings, elicited from interviews, demonstrated that the factors of sentence structure errors extended to students' mother tongue interference, overgeneralization in the use of English rules and norms, and the lecturer's teaching material delivery and method. Anchored in the data gained, this research discussed the data from the perspective of interlanguage theory, wherein some reviews of SLA and EFL pedagogyrelated theories were offered to help lower the factors causing English sentence structure errors in writing skills.

Keywords: Errors, Sentence Structure, English writing skill

\section{INTRODUCTION}

In the field of English learning, writing seems to be the most challenging skill because it demands learners to be engaged in many complex ways in terms of literary and topical knowledge, writing experiences, and English use (Chen \& Yu, 2019). According to Faraj (2015), writing is a way to communicate ideas and perspectives in a written form besides using grammatical rules. In addition, writing is one of the English skills describing illustration and representing ideas, feelings, and plans of a writer. Thus, students can express themselves through writing. In the learning process of writing skills, students describe their knowledge to teachers, and teachers use students' writing products to know the extent of their comprehension and to gain some points as to provide learning reflection for them (Deane, 2018; Graham et al., 2017). In such a way, teachers view students' writing works by drawing upon a formative assessment-informed principle to find better ways to improve students' further learning of English writing in a better way (Burner, 2015; Han \& Fan, 2019). The foregoing also infers that teachers promote students' learning of Error Hence, teachers need to make use of students' writing works as sources to measure students' comprehension and knowledge in terms of learning processes. English writing in terms of both process and product (Al-hroub, Shami, \& Evans, 2017). 
Writing quality consists of some components. They consist of spelling, vocabulary, story structure or organization, and syntax (Chong, 2018). Those components will make good writing work. Of those components, syntax seems to be a major critical element that needs to receive serious attention from a writer. The syntax is the realm of how phases, clauses, and sentences are modified (Hartsuiker, Pickering, \& Veltkamp, 2004). It is one of the linguistics branches oriented towards the ways words are combined into a set of phrases, phrases into clauses, and clauses into sentences so that a good writing work can be produced by modifying those syntactic components (Liao, 2014; Yeo \& Tsoulas, 2013). In addition, how a sentence is constructed in writing is called sentence structure which is part of the syntax. Therefore, if a writing work has no good use of syntactic components, such work will exhibit sentence patterns difficult to be identified, and consequently, the readers will not understand the ideas or meanings conveyed by the writing product.

Sentence structure is the organization in a sentence that consists of words, phrases, or clauses (Datchuk \& Rodgers, 2019; Demirezen, 2012). In a sentence, those linguistic components can be identified as subject, verb, object, adverb, and others. In this respect, sentence structure is part of writing components because it is associated with the way a sentence is constructed. For example, the sentence "The snake killed the rat" contains one independent clause and two phrases. The snake is a noun phrase, and killed the rat is a verb phrase. There are also five words from that sentence which are categorized as noun, verb, and determinant. The words the, snake, the rat are classified into onemorpheme words, whereas killed is categorized as a two-morpheme word.

Sentence structure has some types. The first is a simple sentence. It is a sentence which only has one set of subject and verb, or it is called an independent clause (Depraetere \& Langford, 2020). The sentence "I took a chance" is an example of a simple sentence. The second is a compound sentence. It is a sentence that consists of two or more independent clauses, and they are connected by coordinate conjunctions such as and, but, or, nor, for, yet, so, etc (Jacobs, 2020). An example of a compound sentence can be as follows: "Andy plays football, and I support his team". The third is a complex sentence. It is a sentence consisting of one independent clause and one or more dependent clauses (TorresGouzerh, 2019). Such a combination is mediated by subordinate conjunctions such as when, while, because, although, if, that, and 
whether. For example, the sentence "John came to campus although he had a job" depicts a complex sentence. The last is a compound-complex sentence. It is a sentence consisting of two or more independent clauses and dependent clauses (Osborne, 2019). For example, "Although he was cleaning the kitchen, he found an oil, but he couldn't clean it". Aligned with Murphy (2019), sentence structure is divided into four categories as mentioned above. The mastery of sentence structure modification can lead students to be capable of producing a good English paragraph. According to Napitupulu and Manalu (2018), a paragraph is a group of sentences that develop a central idea. Thus, a paragraph is constructed by some sentences.

Meanwhile, the preliminary study conducted by interviewing an English writing lecturer, the interview revealed that the fourth-semester students at State Islamic Institute (IAIN) of Curup seemed to have problems in modifying sentence structure when they were writing an English paragraph. In addition, in the preliminary study, we also analyzed students' English writing skills from diaries they wrote as a final exam of writing II subject. Students still made errors pertinent to the types of sentence structure. For example, as portrayed from one student's work, he wrote as follows: "Every Friday our department do a dhuha, so I should come". Anchored in this sentence, the error is found in the aspect of subject-verb agreement or the agreement between a noun and a verb phrase. The ideal sentence should be "Every Friday our department does a dhuha, so I should come". The category of this sentence is a compound sentence. In short, the student was still confused about using a singular subject and its verb.

In addition, as another example exhibiting an error a student made in his paragraph writing, a student was found to have written a sentence as follows: "Very tired today because learned with the pronunciation lecturer". Resting upon this sentence, the student made two errors. The first error refers to the construction of the independent clause which has no subject, and the second error refers to the dependent clause which also does not provide a subject after the subordinate conjunction "because". The ideal sentence should be "I am very tired today because I learned with the pronunciation lecturer". There are many more errors found in students' works. The aforesaid sentences are only two examples to represent the phenomenon of this research. This phenomenon calls for more research on sentence structure since this realm is so fundamental in terms of English writing. 
Grounded in the problems highlighted in the phenomenon above, this research is executed to know what types of errors of English sentence structure students make in writing an English paragraph alongside the factors contributing to such errors. We view errors as informed in the theory of interlanguage wherein errors are analyzed as a factor to promote further learning in a better way (Mahmood, Mohammed, \& Murad, 2018; Morganna, 2017), so that the data of the present study could be used by educators to reflect on learning implementation of English writing skill. There are some types of errors that are oriented as the focus of this research. They are omission, addition, misformation, and misordering (Dulay, Burt \& Krashen, 1982).

\section{THEORITICAL FRAMEWORK}

The theories related error analysis are derived from the theories of contrastive analysis. In this section, to make the theoretical presentation breif but clear, we present some theoretical concepts of contrastive analysis first and then followed by those error analysis.

\section{Contrastive Analysis}

According to James (1980: 3) Contrastive Analysis (CA) is always concerned with a pair of languages and founded the assumption that languages can be compared. Richards (1992: 130) emphasizes that CA is the comparison of the linguistic systems of two languages, for example the sound system or the grammatical system. Brown (2000: 208) strengthens those arguments by claiming that the principal barrier to second language acquisition is the interference of the first language system to the second language system. Furthermore, Ellis (1992: 48) says that CA looked at only the learner's native and target language (i.e fully-formed languages). Meanwhile, Lado (1957) reveals that the elements which are similar to the learner's native language will be cushy for him (positive transfer), whereas those different elements will be severe (negative transfer). On the other words, it can be concluded that the second language acquisition can be affected by the L1 transfers.

Moreover, Kebbe (2004: 2) gives more description related to the significant of the CA, that is, L2 instructional materials could be prepared more efficiently by comparing two languages, and, in the process, the learners" behaviors and difficulties could be predicted. Some researchers even assured that when similarities and dissimilarities were taken into account, pedagogy could be beneficial and more effective. 
Unfortunately, this theory got criticism from many linguists who considered the contrastive analysis theory as the backward one because the hypothesis merely regards the cause of language errors is the only differentiation of language system between L1 and L2, whereas the fact shows that the difficulty in learning a language not only faced by the learners who are studying L2 but also they who are studying L1. Furthermore, when CA just dawned in the 1970's, it was being discredited anymore, its theory bubble began to burst and then the presence of the Error Analysis becomes an alternative.

Based on the description above, it can be concluded that the presence of Contrastive Analysis"s theory is boggled by the linguists because its hypothesis merely focuses on the case of interference coming from L1 to L2, whereas the theory of Error Analysis is brought as the second option to conduct a linguistic research because EA provided a methodology for investigating learner language. For this reason EA belongs to an appropriate starting point for the study of learner language and L2 acquisition. To get more study of Error Analysis, the researchers are going to briefly describe it below.

\section{Error Analysis}

According to Ellis (1992: 47-48) error analysis (EA) refers to a study of errors. In line with the previous statement, Richards (1992: 84) defines error analysis as a study and analysis of the errors made by second language learners. Furthermore, EA may be carried out in order to: find out how well someone knows a language, find out how a person learns a language, and obtain information on common difficulties in language learning as an aid in teaching or in the preparation of teaching materials. Corder (1981) notes that a learner"s errors are significant in that they provide to the researcher evidence of how language is learned or acquired, what strategies or procedures the learner is employing in the discovery of the language. On the other words, this term of Error Analysis that has been described before merely focuses on its merit.

On the other hand, Bussmann (1996: 153) reveals that in second language acquisition, Error Analysis studies the types and causes of linguistic errors. This sometimes includes the evaluation and correction of errors. In addition, he emphasizes that error analysis also studies errors made by native speakers without speech disorders and investigates errors in normal speech. 
Corder in Ellis (1992: 48) mentions the steps in conducting an Error Analysis as following:

a. Collection of a sample of learner language

Deciding what samples of language learner to be used for the analysis and how to collect these samples.

b. Identification of errors

Identifying the errors by underlying the error that made by the learners.

c. Description of errors

It involves a comparison of the students" idiosyncratic utterances with a reconstruction of those utterances in the target languages and it needs attention to the surface properties of the students" utterances.

d. Explanation of errors

Explaining the errors by establishing the error source and calculating how often the errors appear.

e. Evaluation of errors

Evaluating the errors step involves labelizing the errors and draw the conclusion.

From these descriptions above, the conclusion related to the error analysis can be drawn, that is, error analysis that belongs to the study of errors in linguistic provides some benefits to the language learner and researcher. To conduct a study of error analysis, the researcher has to also follow the steps or procedures in order to reach the objectives that he/she wants.

\section{RESEARCH METHOD}

The present research applied an explanatory mixed-method design (Creswell, 2007) to delve into students' errors of English sentence structure as they made in writing English paragraphs alongside the factors contributing to such errors. It is a design of mixedmethod study wherein the researchers garner and quantitatively collect the data first, and subsequently, the researchers conducted a qualitative study to probe into more detailed and contextual data (Ary, Jacobs, Sorensen, Walker, \& Razavieh, 2010). In so doing, the quantitative study was conducted using document analysis anchored in the already made construct of sentence structure errors as proposed by Dulay, Burt \& 
Krashen (1982). Resting upon their construct, errors of sentence structure comprise four elements, namely omission, addition, misformation, and misordering. This construct was used to analyze the entire writing works of students. Making use of the already made construct to elicit the data in document analysis demonstrates that this way adopts a positivist worldview, or in other words, a quantitative way. In turn, a qualitative study was undertaken to find out deep and contextual information concerning the factors of students' errors in terms of English sentence structure based upon their English paragraph writing.

The subjects of this research were the fourth-semester students from an English department at IAIN Curup who already took writing II. They consisted of 29 students. The data sources of quantitative document analysis were according to recount texts students wrote as their diaries, wherein such writing works were previously assigned to them in their exams. The characteristic of students writing works was a sort of written recount texts. Each recount text was made in the form of one paragraph with one topic. It was that short and simple because the students were still taking writing II subject when this study was undertaken. All students' writing works were analyzed using Dulay, Burt, and Krashen's (1982) construct of sentence structure error analysis. The data of document analysis were analyzed by means of calculating the percentages of errors, and then the errors were explained appropriately by demonstrating a few examples of the errors (Myers, Well, \& Lorch, 2010). Such little demonstration was provided due to the limited space of this paper.

In terms of qualitative data, the data were gathered from semistructured interviews (Fraenkel, Wallen, \& Hyun, 2012; Gall, Gall, \& Borg, 2003; Oppenheim, 2001) for the sake of getting adequate information as regards the factors contributing to students' errors of English structure. The data were further analyzed by adopting an interactive model analysis as posited by Miles, Huberman, and Saldana (2014). As informed from the foregoing model, the data analysis took four elements comprised of data collection, data condensation, data display, and conclusion drawing.

\section{FINDINGS AND DISCUSSION FINDINGS}

Types of Students' English Sentence Structure Errors 
Anchored in the quantitative document analysis employing Dulay, Burt, \& Krashen's (1982) ready-to-use construct of sentence structure error analysis, the students could write three types of sentences in their writing works. Those types referred to a simple sentence, compound sentence, and complex sentence. In this regard, the students did not seem to have been able to write compound-complex sentences. From the overall sentences' students could write, there were some types of errors as regards English sentence structure they made in their writing works. The percentages of errors are displayed in table 1

Table 1.

The percentages of types of sentence structure errors in students' paragraphs

\begin{tabular}{|c|c|c|c|c|c|c|c|c|c|}
\hline \multirow{3}{*}{$\mathbf{N}$} & \multirow{3}{*}{$\begin{array}{l}\text { Sentence } \\
\text { Structure }\end{array}$} & \multicolumn{8}{|c|}{ Accuracy } \\
\hline & & \multicolumn{5}{|c|}{ Frequency } & \multicolumn{3}{|c|}{ Percentage (\%) } \\
\hline & & $\mathbf{M}$ & D & $\mathbf{F}$ & $\mathbf{0}$ & $\mathbf{M}$ & D & $\mathbf{F}$ & $\mathbf{0}$ \\
\hline & $\begin{array}{l}\text { Simple } \\
\text { Sentence }\end{array}$ & 6 & 9 & 2 & 5 & 5.87 & 7.5 & 1.51 & 8.47 \\
\hline & a. Words & 7 & & & 4 & 3.37 & 6.32 & 3.64 & 8.58 \\
\hline & b. Phrases & & 4 & 4 & & 2.13 & 3.69 & 3.64 & .58 \\
\hline & c. Clauses & & & & & .52 & & 7.73 & 2.86 \\
\hline & $\begin{array}{l}\text { Compound } \\
\text { Sentence }\end{array}$ & 2 & 4 & 7 & 7 & 3.69 & 5 & 2.08 & 9.68 \\
\hline & a. Words & 8 & & & 9 & 3.55 & 2.86 & 9.42 & 0.38 \\
\hline & b. Phrases & & & & & .84 & 7.15 & 2.95 & 8.52 \\
\hline & c. Clauses & & & & & .62 & & 7.65 & 1.12 \\
\hline & $\begin{array}{l}\text { Complex } \\
\text { Sentence }\end{array}$ & 6 & & 4 & 9 & 0.61 & 7.5 & 6.42 & 1.87 \\
\hline & a. Words & 3 & & & 9 & 4.65 & 4.29 & 5.72 & 5.52 \\
\hline & b. Phrases & & & & & .58 & 5.72 & 0 & 7.25 \\
\hline & c. Clauses & & & & & & & & \\
\hline
\end{tabular}


Note :

$\mathrm{OM}:$ Omission

$\mathrm{AD}$ : Addition

MF : Misformation

MO : Misordering

\section{Omission}

The omission is an error by the absence of an item that must appear in a well-formed utterance. The omission error contains subcategories namely omission of a content morpheme (the omission of noun, verb, adjective, and adverb) and omission of a grammatical morpheme (the omission of inflections, article, preposition, verb auxiliaries, and conjunction) (Dulay, Burt, \& Krashen, 1982). Based on table 1, of the overall simple sentences found in students' works, there are $35.87 \%$ of errors were made in terms of omission. Out of all simple sentences with omission errors, there are $83.37 \%$ of omission errors in the domain of words, $12.13 \%$ in the domain of phrases, and $1.52 \%$ in the domain of clauses. Based on the students' works, the most omission errors of simple sentences are the omission of grammatical morphemes such as the omission of noun and verb inflections. Students omitted -s, es, -ed, and -ing. For example, as taken from one student's work, the student wrote "many student can get a new friend". In this case, students omitted the -s of noun. The ideal sentence should be "many students can get a new friend". In addition, of all compound sentences found in students' works, there are $33.69 \%$ of omission errors. Subsequently, out of the overall omission errors of compound sentences, there are $93.55 \%$ of omission errors in the domain of words, $4.84 \%$ in the domain of phrases, and $1.62 \%$ in the domain of clauses. As revealed from their writing works, most students omitted articles, prepositions, and verbs in compound sentences. For example, as taken from one student's work, the student wrote "Bad day is Thursday, and I came to college" instead of "the bad day is Thursday, and I came to college". In such a way, students omitted article on a noun phrase, and there must be added "the". In turn, of all complex sentences found in students' works, there are $30.61 \%$ of omission errors. Out of all complex sentence omission errors, there are $94.65 \%$ of errors in the domain of words, $3.58 \%$ in the domain of phrases, and $1.79 \%$ in the domain of clauses. We found the most 
omission errors on verbs and conjunctions namely subordinate conjunctions in complex sentences. For example, as taken from one student's work, the student wrote "Today I didn't have a good mood in paragraph writing lesson" instead of "today I didn't have a good mood when I learned in paragraph writing lesson". In this sentence, the student omitted verb and subordinate conjunction. The sentence must be added with the verb "learned" and the subordinate conjunction "when" as the connector.

\section{Addition}

The addition is an error that refers to the presence of an element or an item that must not appear in a well-formed utterance. An addition error contains sub-categories such as regularization, double marking, and simple addition (Dulay, Burt, \& Krashen, 1982). In this research, we encountered addition errors in the domain of words and phrases, but we did not find out addition errors in the domain of clauses. Grounded in table 1, there are $47.5 \%$ of simple sentences with addition errors sticking out. Of all addition errors in the aspect of simple sentences, there are $26.32 \%$ of errors in the domain of words and $73.69 \%$ in the domain of phrases. The most addition errors in simple sentences were that students made addition in the regularization of using singular and plural nouns. For example, as selected from one student's work, the student wrote "The students follow a demonstration in Jakarta". The student added "s" in noun and made an addition error on the sentence. The sentence should be "The student follows a demonstration in Jakarta". Subsequently, there are $35 \%$ of addition errors sticking out from the overall compound sentences in students' works. Out of the errors in compound sentences, there are $42.86 \%$ of errors in the domain of words and $57.15 \%$ in the domain of phrases. As to exhibit the example, a student wrote "He used the permanent marker, and that is makes us laughed". In this sentence, there are two tenses or double marker addition, namely "is" and "makes". Therefore, this sentence should be"He used the permanent marker, and that made us laughed". In turn, in terms of complex sentences, there are $17.5 \%$ of errors. Out of all errors in terms of complex sentences, there are $14.29 \%$ of errors in the domain of words and $85.72 \%$ in the domain of phrases. In line with errors on simple sentences and compound sentences, errors of complex sentences comprise double marking and regularization categories. For example, one student wrote "taked by the YSR congress government that is aimed toward improving" instead of "took by the YSR congress government that 
aimed toward improving". The student made a regularization error on word by adding -ed on irregular verb "taked" instead of "took".

\section{Misformation}

Misformation is an error that refers to the use of the wrong morpheme or structure in writing. This error consists of three subcategories. They are regularization, alternating form, and archi-form (Dulay, Burt \& Krashen, 1982). Anchored in table 1, in terms of simple sentences, there are $41.51 \%$ errors found in students' works. Of all simple sentence misformation errors, there are $13.64 \%$ of errors in the domain of words, $63.64 \%$ in the domain of phrases, and $27.73 \%$ in the domain of clauses. For instance, as taken from one student's work demonstrating word-based misformation, the student wrote "their are three mobile phones on the table". The word "their" was used in a misformation way. The ideal sentence should be "there are three mobile phones on the table". In this case, the word "there" referred to the ideal formation. Subsequently, in terms of compound sentences, there are $32.08 \%$ of misformation errors. Out of all misformation errors in the aspect of compound sentences, there are $29.42 \%$ of errors in the domain of words, $52.95 \%$ in the domain of phrases, and $17.65 \%$ in the domain of clauses. In turn, in terms of complex sentences, there are $26.42 \%$ of errors found. Of all complex sentence misformation errors, there are $35.72 \%$ of errors in the domain of words, $50 \%$ in the domain of phrases, and $14.29 \%$ in the domain of clauses. Based on the result of the analysis, the most misformation errors are alternating forms in each type of sentence structure because students used some forms of their vocabularies and grammar. For example "I hope this situation can quick be better" instead of "I hope this situation will be better soon". The students used their own vocabulary "can quick" which made a misformation error, and the words must be "will be" to make the sentence meaningful.

\section{Misordering}

Misordering is an error caused by the wrong placement of a morpheme or a group of morphemes (Dulay, Burt \& Krashen, 1982). From students' works, we found out misordering errors in the form of errors on spelling, lexicon, and structure or syntax. Based on table 1, in terms of simple sentences, there are $38.47 \%$ of errors sticking out. Out of all misordering errors in the aspect of simple sentences, there are 
$68.58 \%$ of errors in the domain of words, $8.58 \%$ in the domain of phrases, and $22.86 \%$ in the domain of clauses. Subsequently, in terms of compound sentences, there are $29.68 \%$ of errors sticking out. Of all the errors made in the aspect of compound sentences, there are $70.38 \%$ of errors in the domain of words, $18.52 \%$ in the domain of phrases, and $11.12 \%$ in the domain of clauses. In turn, in terms of complex sentences, there are $31.87 \%$ of errors found. Out of all complex sentence errors of misordering, there are $65.52 \%$ of errors in the domain of words, $17.25 \%$ in the domain of phrases, and $17.25 \%$ in the domain of clauses. The most misordering errors were those on spellings in the aspects of both words and phrases. For example, as taken from one student's work, the student wrote "I have no question to ask but I got a pen form the lecturer" instead of "I have no question to ask but I got a pen from the lecturer". The student made errors in spelling "from" to "form" that made the sentence convey unclear meaning. Then, we found misordering errors on clauses. For example, a student wrote, "Should we have 4 lecturers to teach today but two lecturers did not come". The sentence structure is wrong due to the subject position. This sentence should be "we should have four lecturers to teach today but two lecturers did not come".

\section{The Factors Contributing to Sentence Structure Errors in Students' Paragraphs}

The data pertinent to factors contributing to students' sentence structure errors were garnered from interviews. Drawing upon Miles et al. (2014) interactive model which suggested us to code some themes representing the data, the data were then coded. The coded themes concerning such factors extended to mother tongue interference, overgeneralization, and teaching materials or method, the following elaborations present the interview data alongside some properly related explanations.

\section{Mother tongue interference}

Based on the interview, most of the students answered that the factors of errors in sentence structure were caused by some aspects related to mother tongue. The first was the aspect of culture. The following is a student's answer when we asked about the culture of their mother tongue (Indonesian language) influencing his writing:

"Yes, of course, I always use the Indonesian language before writing in English. Then I translate into English. I use the Indonesian language 
because it makes me get a better understanding, and other people don't understand my writing if I directly write in English."

Concerning the statement above, we got that culture was one of the points that affected errors in sentence structure in writing the paragraph. The students usually applied their mother tongue, for example, students wrote the Indonesian language including the words, phrases, and clauses first, and then translated them into English. Hence, the result of translation would be different from ideal English.

The second aspect was language structure. The language structure became one of the error factors on sentence structure in writing. As regards this point, when we asked about Indonesian language structure influencing her writing, a student answered as follows:

"Of course, I use Indonesian language structure if I write in English be it influences in my writing and sometimes it arises naturally when I write in English. In addition, using the structure of Indonesian language is certainly easier for me, and I think, the structures between Indonesian and English are almost similar so that this helps me."

From the statement above, we concluded that the student assumed that the structures between English and Indonesian were similar. The structures of Indonesian and English are different. For example, in the structure of the Indonesian language, there are no noun and verb inflections, but English has the rules of noun and verb inflection (-s/-es, -ed, -ing) wherein noun shows plural and singular, and verb shows tenses. Thus, the structure of the Indonesian language became the major factor of errors influencing sentence structure in paragraph writing.

The last aspect of the mother tongue was vocabulary. We asked the students about the word choice (vocabulary) that they used in writing. The answer of a student is as follows:

"I usually use vocabulary from the internet such as the trendy words (viral) and also I use vocabularies that I have in my mind and sometimes I accidentally put Indonesian words in writing"

Regarding the student's statement, we concluded that the vocabulary aspect contributed to errors in sentence structure in writing the paragraph. The students used the vocabularies that they had without checking them into the dictionary. This condition at some point led to errors of word spellings so that the words could be meaningless. In addition, students used Indonesian vocabulary directly, and they 
thought the spellings were correct. These factors made errors in sentence structure in writing.

\section{Overgeneralization}

Overgeneralization refers to a process of creating a new language by students in their mind and producing rules themselves along with learning based on evidence. In overgeneralization, students had a new strategy in writing that made errors in sentence structure. We asked a student about the use of his strategy in writing English. The answer is as follows:

"I don't have a specific strategy in writing, but I usually think what I want to write and immediately write what comes to my mind. This strategy makes me easier to write in English"

Based on the statement above, we concluded that the student's strategy caused errors in sentence structure. The students had a strategy, for example, they wrote directly without paying attention to techniques before writing like listing and mind mapping. This technique would make the writing more organized especially the sentence structure and also would avoid writing errors.

\section{Teaching materials or method}

The errors were also caused by teaching materials or methods. This factor contained two aspects. They were inappropriate explanations of the lecturer and the faulty materials. The first was inappropriate explanations of the lecturer. The students stated that they made errors because they did not understand the materials from the writing lecturer, and they did not master their writing skills well. We asked a student about the technique and method used by the writing lecturer. The answer is as follow:

"Of course I like the methods and techniques of the writing's lecturer, for example, they applied games to deliver materials and made our enthusiasm, but if talking about the understanding of the materials, I thought I don't understand and about 30\% of the materials as delivered by the lecturer, and maybe it's too fast"

Concerning the student's statement, we concluded that the explanations given by the writing lecturer were good but seemed to be inappropriately delivered. In addition, in delivering the materials, the writing lecturer did it too fast so that the student did not understand. The lack of understanding of students led to errors in writing. 
The second aspect was faulty materials. The following is the answer from a student when we asked about the source of materials in writing subject:

"I prefer internet than the books as the source because on the internet we can search for the materials of writing subject because it is very completed. If we are confused, we can search on the internet"

Based on the student's answer, we got that the students only used the internet as the source of the learning process. The students thought that the internet was a good source than others. They did not know the source of the blog. At some point, the materials on the internet were not valid and would plausibly contribute to errors in their writing.

In conclusion, the factors that made errors on sentence structure in writing paragraph extended to mother tongue interference, overgeneralization, and teaching materials or method. Based on the results of interviews, we concluded that the most factors causing students' errors in sentence structure in writing paragraphs covered mother tongue interference. The foregoing ranged from culture, language structure, to vocabularies.

\section{DISCUSSION}

The present research revealed that in writing English paragraphs as seen from the recount diary texts they wrote, the students made errors of English sentence structure in all categories of errors extending to omission, addition, misformation, and misordering. Each error category represented proximate percentages which meant that students on average had problems in all categories of errors. Those errors resting upon the categories were also affiliated with three types of sentences as they exhibited in their works. Those types of sentences extended to simple sentences, compound sentences, and complex sentences. Unfortunately, in their writing works, students were not capable yet of using compound-complex sentences. The findings of this research echoed many of prior findings in terms of English sentence structure errors such as the studies conducted by Hendrawaty (2018); Putri and Dewanti (2014); Silalahi (2014); and Wulandari (2014). It seems that Indonesian English students at the levels of both secondary and tertiary in general still have similar problems in terms of making errors in writing English sentence structure. This research infers that English pedagogy in Indonesia needs better improvement to help students in terms of English writing skills. 
The other set of findings this research found addressed the factors contributing to students' English sentence structure errors in their writing works. There are three main data that this research uncovered concerning the factors, namely mother tongue interference, overgeneralization, and difficult teaching materials delivered by the lecturer. Concerning the first factor, mother tongue interference, Kramsch (2013) names it an influence of a deep culture already embedded in oneself. Based on the perspective of interlanguage theory as echoed by Fauziati (2014) and Morganna (2017), the mother tongue is a natural and inborn cultural affiliation that can determine the extent to which one is skillful at his English interlanguage development. Many experts have offered solutions to help learners lower their first language interference so that both of their spoken and written English improve well. To name a few, those experts are Stephen Krashen (for further reading, see Edwards, Wesche, Krashen, Clement, \& Kruidenierr, 1985; Krashen, 1981, 1982, 2004; and Mason \& Krashen, 1997) and Paul Nation (for further reading, see Laufer \& Nation, 1995; Nation, 2001, 2014; Webb \& Nation, 2017). Krashen has introduced his comprehensible input theory wherein English learning processes, for instance, learning English writing skills in this research context, need to be brought into the concept of immersion to Native English. In the same vein, Nation also supported that learning English should be done in an immersive way so that native-like English input and output can be reached by learners in terms of both receptive skills and productive skills including writing skills if grounded in the context of this research.

For the second factor, it is also a natural problem that commonly occurs in the circle of English as a foreign language users. This one is called natural creativity (Byram, 1986; Crystal, 2008; Kachru, Kachru, \& Nelson, 2006; Kachru, 1990). Overgeneralization is a kind of developmental process of students' English interlanguage (Mahmood et al., 2018; Yang, 2014). This factor can be lowered if students have been given adequate English input for instance reading skill by using nativelike authentic texts, and the students are led to immerse those texts, so that the students ultimately will be capable of producing native like English writing products which are free from overgeneralization of English forms or structures and also free from any non-native English creativity.

Subsequently, the third factor is teaching materials. Some students in this research echoed that the lecturer to some extent presented the materials during teaching English writing in a way that 
was too fast so that they found it difficult to grasp the materials, and as a consequence, their less understanding of the materials caused them to produce unexpected writing products with many errors of English sentence structure. It seems that the paradigm of English writing material delivery adopted by the lecturer should be changed. Today, many experts suggest that English writing skill needs to be taught using socio-cultural paradigm as informed by Lantolf and Thorne, 2006; Turuk, 2008; and Vygotsky (1978). In this way, students are expected to be engaged in the process of knowledge and skill construction as offered by genre-based instruction in terms of English writing instruction (Morganna, 2017b; Uzun \& Topkaya, 2019; Worden, 2018).

Broadly speaking, the three impeding factors contributing to students' errors in terms of English sentence structure can be solved if dug into the existing English pedagogic theories. However, to lower those factors, an English writing lecturer needs to keep improving his/her English writing pedagogic knowledge and competencies. As discussed above, the factor such as mother tongue interference which worsens students' writing works can be solved by applying immersion learning theory into practice. The factor as regards overgeneralization can be lowered by embedding authentic native English texts as the input so that students writing products can lead to being natural like native English writing products as long as students are led to immerse the English input. Lastly, the factor vis-a-vis challenging English writing material delivery can be addressed by adopting a socio-cultural learning paradigm employing applying genre-based instruction for teaching English writing skills.

\section{CONCLUSION}

Regarding the findings and discussion concerning errors of sentence structure in students' written paragraphs, we conclude that the types of errors contain omission, addition, misformation, and misordering. Omission has a percentage of $50 \%$. There are $35.87 \%$ of simple sentences, $33.69 \%$ of compound sentences, and $30.61 \%$ of complex sentences found to be the errors of content morpheme and grammatical morpheme in words, phrases, and clauses. The percentage of addition errors is about $10.87 \%$ that includes $47.5 \%$ of simple sentences, $35 \%$ of compound sentences, and $17.5 \%$ of complex sentences. Students make addition errors, namely regularization, double marker, and simple addition. Misformation has a percentage of $14.41 \%$. 
Misformation includes regularization, alternating form, and archi form. There are $41.51 \%$ of simple sentences, $32.08 \%$ of compound sentences, and $26.42 \%$ of complex sentences. The last is misordering which has a percentage of $24.73 \%$. There are $38.47 \%$ of simple sentences, $29.68 \%$ of compound sentences, and $31.87 \%$ of complex sentences. Misordering errors include the domains of spellings and structure or syntax. Students' errors in English sentence structure are caused by some factors. The first is mother tongue interference, namely culture, language structure, and vocabularies. The second is overgeneralization such as students' writing strategies. The last is teaching materials and methods in the learning process. There are inappropriate explanations of the lecturer and faulty material delivery.

\section{REFERENCES}

Al-hroub, A., Shami, G., \& Evans, M. (2017). The impact of the 'writers' workshop' approach on the L2 English writing of upper-primary students in Lebanon. The Language Learning Journal, 1-13. https://doi.org/10.1080/09571736.2016.1249394

Ary, D., Jacobs, L. C., Sorensen, C. K., Walker, D. A., \& Razavieh, A. (2010). Introduction to research in education. Measurement (8th ed., Vol. 4). USA: Wadsworth, Cengage Learning. https://doi.org/10.1017/CB09781107415324.004

Burner, T. (2015). Formative assessment of writing in English as a foreign language. Scandinavian Journal of Educational Research, 123. https://doi.org/10.1080/00313831.2015.1066430

Bussmann, H.(1996).Routledge dictionary of language and linguistics.London: Routledge.

Byram, M. (1986). Cultural studies in foreign-language teaching. Language Teaching, 19, 322-336. https://doi.org/10.1017/S0261444800011101

Chen, W., \& Yu, S. (2019). Implementing collaborative writing in teachercentered classroom contexts: student beliefs and perceptions. Language Awareness, $1-21$. https://doi.org/10.1080/09658416.2019.1675680 
Chong, S. W. (2018). The use of exemplars in English writing classrooms: from theory to practice. Assessment \& Evaluation in Higher Education, $1-16$. https://doi.org/10.1080/02602938.2018.1535051

Corder, S. P. (1981). Error analysis and interlanguage. Oxford: Oxford University Press.

Creswell, J. W. (2007). Qualitative inquiry \& research design: Choosing among five approaches (2nd ed.). USA: SAGE publications, Inc.

Crystal, D. (2008). Two thousand million? English Today, 24(01), 3-6. https://doi.org/10.1017/S0266078408000023

Datchuk, S. M., \& Rodgers, D. B. (2019). Text writing within simple sentences: A writing fluency intervention for students with high-incidence disabilities. Learning Disabilities Research \& Practice, 34(1), 23-34.

Deane, P. (2018). The challenges of writing in school: conceptualizing writing development within a sociocognitive framework. Educational Psychologist, 1-21. https://doi.org/10.1080/00461520.2018.1513844

Demirezen, M. (2012). An analysis of the problem-causing structures of simple sentences for Turkish university Students. International Journal of Humanities and Social Science, 2(3), 135-146.

Depraetere, I., \& Langford, C. (2020). Advanced English grammar: A linguistic approach. USA: Bloomsbury Publishing Plc.

Dulay, H., Burt, M., \& Krashen, S. D. (1982). Language two. New York: Oxford University Press.

Edwards, H., Wesche, M., Krashen, S., Clement, R., \& Kruidenierr, B. (1985). Second-language acquisition through subject-matter learning: a study of sheltered subject matter classes at the University of Ottawa. The Canadian Modern Language Review, 41, 268-282.

Ellis, R. (1992). Instructed second language acquisition. UK: BLACKWELL. 
Faraj, A. K. A. (2015). Scaffolding EFL Students' Writing through the Writing Process Approach. Journal of Education and Practice, 6(13), 131-141.

Fauziati, E. (2014). Methods of Teaching English as a Foreign Language. Surarta: Era PustakaUtama.

Fraenkel, J. R., Wallen, N. E., \& Hyun, H. H. (2012). How to design and evaluate research in education. 1221 Avenue of the Americas, New York, NY 10020: McGraw-Hill Companies, Inc. https://doi.org/10.1017/CB09781107415324.004

Gall, M. D., Gall, J. P., \& Borg, W. R. (2003). Educational research: An introduction (7th ed.). USA: Allyn and Bacon.

Graham, S., Liu, X., Aitken, A., Ng, C., Bartlett, B., Harris, K. R., \& Holzapfel, J. (2017). Effectiveness of literacy programs balancing reading and writing instruction: A meta-analysis. Rreading Research Quarterly, 1-26. https://doi.org/10.1002/rrq.194

Han, C., \& Fan, Q. (2019). Using self-assessment as a formative assessment tool in an English-Chinese interpreting course: student views and perceptions of its utility. Perspectives, 1-17. https://doi.org/10.1080/0907676X.2019.1615516

Hartsuiker, R. J., Pickering, M. J., \& Veltkamp, E. (2004). Is Syntax Separate or Shared between Languages? Cross-Linguistic Syntactic Priming in Spanish-English Bilinguals. Psychological Science, 15(6), 409-414.

Hendrawaty, N. (2018). An analysis on students' errors in writing sentence patterns. LOQUEN, 11(1), 63-85.

Jacobs, M. (2020). English grammar rules \& mistakes: learn all of the essentials: writing, speaking, literature and punctuation rules complete with 10 key skills and over 200 common error examples. UK: Independently publisher (Jacobs, Melony ).

James , C. (1980). Contrastive analysis. Singapore: Longman Group Ltd.

Kachru, B. B., Kachru, Y., \& Nelson, C. L. (2006). The handbook of world Englishes. Oxford: Blackwell. 
Kachru, Braj B. (1990). World Englishes and applied linguistics. World Englishes, 9(1), 3-20.

Kramsch, C. (2013). Culture in foreign language teaching. Iranian Journal of Language Teaching Research, 1(1), 57-78.

Krashen, S. D. (1981). Second language acquisition and second language learning. California: Pergamon Press Inc.

Krashen, S. D. (1982). Principles and practice in second language acquisition. California: Pergamon Press Inc.

Krashen, S. D. (2004). The power of reading: insights from the research. London: Heinemann Publishers Ltd.

Lado, R. (1957). Linguistics acrosscultures: Applied linguistics for language teachers. Ann Arbor, MI:University of Michigan Press.

Lantolf, J. P., \& Thorne, S. L. (2006). Sociocultural Theory and Second Language Learning. Theories in Second Language Acquisition, 197221. https://doi.org/10.1177/0022219409345018

Laufer, B., \& Nation, P. (1995). Vocabulary size and use: Lexical richness in L2 written production. Applied Linguistics, 16(3), 307-322.

Liao, W. R. (2014). On modification with whole / zheng in English and Chinese and the uniformity of syntax. J East Asian Linguist, 1-22. https://doi.org/10.1007/s10831-014-9122-x

Mahmood, A. H., Mohammed, I., \& Murad, A. (2018). Approaching the Language of the Second Language Learner: Interlanguage and the Models Before. English Language Teaching, 11(10), 95-108. https://doi.org/10.5539/elt.v11n10p95

Mason, B., \& Krashen, S. (1997). Extensive reading in English as a foreign language. System, 25, 91-102.

Miles, M. B., Huberman, A. M., \& Saldana, J. (2014). Qualitative data analysis: A methods sourcebook. Thousand Oaks, California 91320: SAGE Publications, Inc.

Morganna, R. (2017a). Teachers' attitudes towards conducting interlanguage analysis to prepare better instructions. International 
Journal of Pedagogy and Teacher Education (IJPTE), 1(2), 127-138. https://doi.org/http://dx.doi.org/10.20961/ijpte.v1i2.15080

Morganna, R. (2017b). Theoretical, pedagogical, practical views, and the shift of genre based instruction. English Franca, 1(1), 81-100. https://doi.org/http://dx.doi.org/10.29240/ef.v1i1

Murphy, R. (2019). English grammar in use: Book with answers and interactive ebook: A self-study reference and practice book for intermediate learners of English. UK: Cambridge University Press.

Myers, J. L., Well, A. D., \& Lorch, R. F. (2010). Research desgin and statistical analysis. New York: Routledge.

Napitupulu, S., \& Manalu, D. B. (2018). Students' Paragraph Structure in Writing Research Background. LPPM Universitas HKBP Nommensen.

Nation, P. (2001). Learning vocabulary in another language. Cambridge: Cambridge University Press.

Nation, P. (2014). What do you need to know to learn a foreign language? New Zealand: School of Linguistics and Applied Language Studies Victoria University of Wellington.

Oppenheim, A. N. (2001). Questionnaire design, interviewing and attitude measurement. London: Continuum.

Osborne, T. (2019). A dependency grammar of English: An introduction and beyond. UK: John Benjamins.

Putri, P. S., \& Dewanti, A. (2014). An analysis of grammatical errors in writing narrative texts done by the second semester students at the diploma program English department in Airlangga University Surabaya. Anglicist Volume, 3(1), 1-7.

Richards, J. C, Platt, J. \& Platt, H. (1992). Dictionary of language teaching and applied linguistics. Essex: Longman.

Silalahi, R. M. (2014). Error analysis on information and technology students' sentence writing assignments. IJEE, 1(2), 1-16.

Torres-Gouzerh, R. (2019). Practice Makes Perfect: Intermediate English Grammar for ESL Learners. UK: McGraw-Hill Education. 
Turuk, M. C. (2008). The relevance and implications of Vygotsky's sociocultural theory in the second language classroom. ARECLS, 5, 244-262.

Uzun, K., \& Topkaya, E. Z. (2019). The Effects of Genre-Based Instruction and Genre- Focused Feedback on L2 Writing Performance. Reading \& Writing Quarterly, 1-24. https://doi.org/10.1080/10573569.2019.1661317

Vygotsky, L. (1978). Interaction between learning and development. Readings on the Development of Children. New York. https://doi.org/10.1016/S0006-3495(96)79572-3

Webb, S., \& Nation, P. (2017). How vocabulary is learned. Oxford: Oxford University Press.

Worden, D. (2018). Balancing stability and flexibility in genre-based writing instruction: A case study of a novice L2 writing teacher. Journal of Second Language Writing, 1-14. https://doi.org/10.1016/j.jslw.2018.09.003

Wulandari, I. (2014). Grammatical errors found in articles' abstracts of Indonesian scholarly journals. JEELS, 1(1), 12-30.

Yang, S. (2014). The Functions of the Nontarget Be in the Written Interlanguage of Chinese Learners of English. Language Acquisition, 21, 279-303. https://doi.org/10.1080/10489223.2014.892942

Yeo, N., \& Tsoulas, G. (2013). The syntax of distributivity in a contact variety of English. Lingua, 127, 14-38. https://doi.org/10.1016/j.lingua.2013.01.004 